\section{Thinking about generations, conjuncturally: A toolkit}

\author{
João Pina-Cabral
}

Institute of Social Sciences, University of Lisbon, Portugal
The Sociological Review

$1-19$

(C) The Author(s) 2021

(c) (1)

Article reuse guidelines: sagepub.com/journals-permissions DOI: $10.1177 / 00380261211062301$ journals.sagepub.com/home/sor

(SAGE

\title{
Dimitrios Theodossopoulos
}

School of Anthropology and Conservation, University of Kent, UK

\begin{abstract}
Since the early twentieth century, generation has been a recurrent concept in social analysis. In spite of successive bouts of critique and periods of relative neglect, the category has never been abandoned. In this article, drawing inspiration from a broad range of thinkers - such as José Ortega y Gasset, Karl Mannheim, Antonio Gramsci, Pierre Bourdieu, Raymond Williams and Stuart Hall - we review and fine tune our conceptual toolkit regarding generations, making more explicitly visible its affordances for social analysis in times of crisis. We focus on the problem of intergenerational overlap of contemporaneity and the contradictions that emerge from it. We argue that the notion of coevalness can help us resolve some of these contradictions - for example, the lag between contemporaneity and generational awareness - and introduce, through its horizontal connotations, a decolonising ethical stance. Favouring a processual understanding of generation, we recommend 'conjunctural analysis' as the most flexible analytical framework for resolving the intersectional contradictions and overlaps of generational categorisation.
\end{abstract}

\section{Keywords}

coevalness, conjunctures, contemporaneity, crisis, generations, hegemony, intergenerational overlap

Of late, after a long period of relative absence, the concept of generation seems to be again on everyone's lips. Writing during the pandemic we read the headlines of The Guardian and Observer Charity Appeal for 2020: 'help us prevent COVID creating a lost generation of young people'. The accompanying article warns us against the stark

\footnotetext{
Corresponding author:

Dimitrios Theodossopoulos, School of Anthropology and Conservation, University of Kent, Marlowe Building, Canterbury, Kent CT2 7NR, UK.

Email: D.Theodossopoulos@kent.ac.uk
} 
increase in social inequalities - racial, ethnic, gendered, regional - that past decades have witnessed and that the pandemic crisis has exacerbated (Katharine Viner, The Guardian, 5 December 2020). ${ }^{1}$ This sense of urgency that Viner's words convey is hardly unique. A consensus seems to have emerged concerning how, over the past decades, the globalisation of financial capitalism, the environmental crisis, and the implementation of wideranging 'austerity' policies have led to a drastic increase in inequalities of all kinds. In fact, some analyses have even revealed that distinct expressions of 'generational grievance' have emerged of late with considerable impact in social media (see Elliott, 2021). It would seem that, in moments such as these, when deep upheavals are driving profound social changes, the question of generations comes to the fore. Indeed, this was the case in the 1970s, in the 1930s, and even earlier, at the time of the Napoleonic invasions (see Elder, 1999; Wohl, 1979). Once more today we feel compelled to engage analytically with generation, aiming to outline some of the contradictions it fosters, but also some of the analytical advantages it holds for social theory.

Mindful of our comparative experiences in the UK, Portugal and Greece, we trace the concept's history in order to propose a reading based on a conjunctural approach that may cast analytical light on some of the legitimate concerns that explain why generation has, once again, received considerable attention. We feel that in the current conjuncture of multiple, overlapping crises - austerity policies, global warming, the pandemic - a reappraisal of earlier conceptual work can inspire new debates about the concept of generation and its relationship to crisis.

Thus, in this article, we start from an overview of some of the more influential theoretical formulations of 'generation' in key texts of twentieth century social theory works by José Ortega y Gasset, Karl Mannheim, Antonio Gramsci, Pierre Bourdieu, Raymond Williams and Stuart Hall. Based on this foundation, we identify a general problem in the literature on the topic: there is an ambivalent overlap between a felt sense of contemporaneity and generational awareness. Members of different generations often share elements of a similar generational consciousness, as Mannheim (1923/1953) recognised in the 1920s. Contrastingly, members of the same generation may feel socially distant to each other, even refusing to accept their coevalness, as Bourdieu's thinking outlines (2002). Such contradictions have contributed towards a reserved attitude towards the conceptual application of 'generation', as sociologists and anthropologists before us have observed (Edmunds \& Turner, 2002; see also Kertzer, 1983; Lamb, 2015; Pilcher, 1994; White, 2013, 2017).

Our focus on the question of contemporaneity and generational overlap is fine-tuned by using Fabian's work on coevalness (1983): that is, the disposition to see other people as living in a commensurable time. Framed within a post-colonial critique, Fabian invites the analyst to view underprivileged Others as inhabiting the same temporal frame as the analyst (in a horizontal, de-exoticised, co-responsible manner); thus adding clarity to the contradictions between emerging generational awareness and intergenerational coexistence. If properly registered, the differentiation between coevalness and contemporaneity reveals generational meanings as underdetermined, an analytic position that encourages an appreciation of complexity and a nuanced view of power and historicity. We feel that this is a necessary step if we hope to decolonise academic work and implement a measure of horizontal commensurability in our research encounters with those we study. 
In what follows, we address the experience of being part of the same (or distinct) times by reference to the notions of coevalness, structure of feelings, and conjuncture. In this regard, we see generations as reflecting the complexity of temporal coexistence in the same way as ecumene reflects spatial coexistence (see Mintz, 1996; Pina-Cabral, 2014). We address the problem of overlapping generational awareness by drawing inspiration from twentieth century social theory. Led by Stuart Hall (Hall \& Massey, 2010; Hall et al., 1978), we suggest that thinking conjuncturally allows us to place the real people we study - but also ourselves and our analyses - within the history of the production of meaning about what is a generation. Such a conjunctural awareness can inspire an appreciation of coevalness and allow us to showcase the plurality and interconnections of meaning and intersectional positions, but also the material conditions that shaped their production and reproduction. Seen from such a processual analytical standpoint, generations are always in the process of becoming: they are continually transformed and replaced by subsequent generations that may be less (or more) aware of themselves and share overlapping structures of feeling (see Williams, 1977, 1979). Understanding generations in their multilayered complexity, as articulating with more than one set of meanings, can open the way for understanding the succession of hegemonies - conceived, in Gramscian terms, as the material and ideological conditions of knowing.

\section{Coevals and contemporaries}

A concern with generational succession has been a matter of learned discussion from when Oedipus gave his famous answer to the Sphynx: the creature that walks on four feet in the morning, two feet at midday, and three feet in the evening, is undoubtedly the human being (o $\alpha v \theta \rho \omega \pi \mathrm{s})$ ). In the social sciences, ever since the days of Van Gennep (1909), this has often been associated to a 'life-course approach', which has yielded a number of very valuable insights, leading on to a series of important developments in cohort analysis $^{2}$ as much as in the analysis of ritual (e.g. Ellen, 2012). Nevertheless, a number of social thinkers have alerted us to the dangers of a mechanistic conception of biological determinism, of atomistic individualism, or of a representationalist approach to self-awareness. Through a process of critique and counter-critique, a consensus has emerged regarding generational thinking that encourages us to foreground the historicity of persons and collectivities as these articulate constitutively in specific spatiotemporal moments of social encounter.

Inspired by Stuart Hall's systematisation of the thought of Antonio Gramsci, we see a conjuncture as an emerging social condition, which identifies a constellation of politicoeconomic-cultural forces that correspond to a particular condensation of contradictions. ${ }^{3}$ Conjunctural analysis can help us hone further the distinction between coevalness and contemporaneity broadly associated with postcolonial critique (Fabian, 1983). Midcentury Euro-American scholars, Fabian argued, were generating asynchronous temporalities that produced duplicitous standards of analysis. Suppressing the coevalness of their subjects, social scientists banished exotic cultures (and underprivileged classes) to an 'other' time, generating an allochronic condition. Fabian's critique brought together a concern with personal experience and a deep awareness of the history of globalisation. For him, being coeval is not only a condition, but an ethical injunction; more than living 
in the 'same' time, it means encountering similar affordances in our world. It presupposes substantial commensurability, an ability to share nuanced comparisons, a sense of cohabitation and co-responsibility.

The two authors of the present article are 'coevals' in the sense that Fabian gave the word (1983) but not contemporaries. We share similar experiences in having been born in southern Europe before working as academics in the United Kingdom, and over the last few years, working at the same university, living in the same town, we experienced the successive crises of Brexit and the Covid-19 pandemic. However, an age difference of 15 years locates us in different positions in our life-courses, both in terms of familial and of academic relations (see Bourdieu, 1988; Pina-Cabral \& Bowman, 2020). The older author was brought up in Africa (Mozambique), under colonial and dictatorial conditions. Decolonisation and democratisation were foundational aspects of his choice of anthropology as a lifelong vocation. The younger author came of age in a postcolonial, neoliberal context (Greece) and environmental militancy was at the source of his anthropological vocation. At a moment when the older author is approaching retirement, the younger author will have to face the profound challenges that the present moment poses to the higher education sector in the United Kingdom.

The conjunctures that each one of us had to respond to during our lives and the people we interacted with during our more decisive moments were both similar and different. Thus, we find ourselves as members of one generation in a certain sense, for we were residents in southeast England at the time of writing. Yet, in a different sense, our generational inscriptions diverge. That is, in looking reflexively at ourselves, the very same conjuncture that unites us also differentiates us. Each one of us is a member of generations in places the other is not (namely, Portugal vs Greece, or Oxford vs the LSE - see Pina-Cabral \& Bowman, 2020). In spite of such differences, we are coevals, in the sense that we inhabit a world where we are ethically called to respond to each other - we are company to each other. This means that the notion of generation must be understood as subject to scalar diversification. People that, in some sense, are members of the same generation, for other purposes, at other times, and before other people, turn out to be generationally divergent.

Therefore, are we (or are we not) bearers of different 'generational consciousnesses'? Our example precisely highlights the problems with fastening 'consciousness' onto space time, for it freezes artificially - as Williams (1977) would say - the dialectic process of social becoming, of which both of us are active shapers and passive responders - and of which this article is a part. We find that a representationalist approach to 'generation-for-itself', i.e. an explicitly frozen generational identity: as in, Generation X, Y, or Z, obscures the plasticity of the process of generational constitution - that is, the fact that we are always meeting people whose position before the world is largely the same as ours and people whose position is not. Clearly, not all contemporaries are coevals, for time too is socially perceived. A person's generational awareness is fluid (intersubjectively and historically constituted), but also reflexive: we all respond to emergent conjunctures of which we were - to some small degree - co-constitutive agents.

In bringing generations and conjunctures together, our principal motivation is to grasp how moments of social upheaval (crises) bring about changes in social dispositions and how these, in turn, reflect themselves on personal lives as something for which one 
had not planned, something that breaks through one's previous futuricities, opening and closing pathways. We believe that, by devoting analytical attention to such moments of rapid transformation and to the sense of chance they evoke (see Elder 1999), one can gain unique insights on alternative understandings of space and time (Hall \& Massey, 2010). Thus, we focus on 'historicity' rather than adopting a more formal historicism (see Hirsch \& Stewart, 2005; Palmié \& Stewart, 2016; Stewart, 2016). Our use of the conjunctural approach depends upon a view of generational historicity that does not naturalise space, time and materiality (see Barad, 2007; Pina-Cabral, 2017) and captures the coexistence and complicity of local meaning with dominant narratives and explanations (Theodossopoulos, 2020).

One of the fundamental problems of generation - conceived as an analytical term has been the propensity to conflate ethical commensurability in the social encounter (coevalness) with presence at a particular chronological time (contemporaneity). In studies focusing on ageing, childhood and the life-course, generation has often been used as equivalent to age group or cohort (see Burnett, 2016; Turner, 2002), a use that can be traced back to a mid-twentieth century proneness to naturalise the individual. Whilst many anthropological analysts of the life-course and of generational succession were aware of the problem (see Lisón-Tolosana, 1966/1988; Needham, 1974), it has not always been possible to fully avoid this naturalisation (see Goody, 1971). Moreover, generational thinking has often been critiqued for exaggerating the connotations of social and political succession (see Pina-Cabral \& Lima, 2000). A derivative analytical concept

- 'generationalist' - has even been developed to refer to thinkers who rely too heavily on generational thinking (Wohl, 1979), giving rise to versions of generational historicism (Hazlett, 1998), or exaggerating the aetiology of generational determinations in political narratives (Bristow, 2020; Purhonen, 2016; White, 2013). We agree with these authors that 'generationalism' can indeed essentialise contemporaneity at the expense of a focus on social interaction; communicating a deterministic view of 'lost' generations (see also Nilsen \& Brennan, 2014), as does the Guardian appeal in the opening quotation of the article.

Nevertheless, we are unhappy with Wohl's (1979) categorisation of Gramsci, Ortega y Gasset and Karl Mannheim as 'generationalists'. We find that this style of academic history-making is prone to caricature the work of authors who remain deeply inspirational today. Thus, we will examine their work in search of suggestions for thinking analytically about the concept of generation. As it happens, the way they theorised the concept of generation fully recognises the ambiguous and socially mediated relationship of coevalness with contemporaneity. There is a lot to be gained from engaging their work; quite as much as there is from understanding how a subsequent generation of thinkers - Meyer Fortes, Pierre Bourdieu, or Raymond Williams, who did not theorise generations explicitly - dealt in their writings with the matter of coevalness.

\section{Generational conjunctures and coevalness}

Gramsci's (1973) concept of conjuncture captures the idea of a dynamic system where certain factors combine spatiotemporally to create certain effects, for example, particular configurations of power. The changes of rhythm that mark specifiable conjunctures and 
differentiate them from each other are not simply breaks in time: they contrast with a kind of stability, a given type of (more) permanent structure - or, in terms of Gramsci's political methodology, more stable, 'organic movements' (1973, pp. 177-178). Conjunctural crises challenge social stability and present an opportunity to maintain or transform the established configurations of power. The term 'conjunctural' - as used by Gramsci mostly in adjectival form - reminds us that temporality is related to the constraints set by a status quo, a spatiotemporal condition that is characterised by the synergy and entanglement of the different recognisable features, which scaffold sociality. ${ }^{4}$ As in physics, no form of stability is ever permanent or absolute; entanglement is the ultimate condition of social existence. Yet, in social life, forms of relative stability do emerge (as with symmetries in physics - see Riehl, 2010) and they can be recognisable both at an everyday level and at an analytical level. To the extent that they encounter each other, coevals respond to an emergent conjuncture; to put it in Fabian's terms, they 'share a present Time' (with capital - Fabian, 1983, pp. 31-33).

Gramsci's understandings of conjuncture are linked to his notion of hegemony. The latter aims to account for the pervasive perpetuation of power and the articulation of all those conditions - material or symbolic - that make this possible, including the process by which we give consent to our domination, or unwittingly participate in the domination of others. Hegemony, as conceived by Gramsci, pervades collective living; it affects the actions and ideas of particular persons, although seldom can these be directly pinpointed to identifiable interpersonal relations. We would like to underline that conjunctures, as moments of sharing (actions, events, ideas), are recognisable by those who cohabit them. Conjunctures carry a zeitgeist (the spirit of the moment); they make particular social periods recognisable to persons in their continued specificity. Coevals may openly theorise their coevalness in the structuring experience of particular conjunctures, but they do not always recognise the workings of hegemony - or not to the same degree.

Coevalness is predicated, as Fabian puts it, on the recognition that 'all temporal relations, and therefore also contemporaneity, are embedded in culturally organised praxis' (1983, p. 34). Because coevals undergo a common occupation of space-time, they encounter similar affordances, that is, a similarly scaffolded world. Yet not all contemporaries are coevals, since personal time is a time of life and it is therefore syncopated. During any particular period, there are contemporaries that are situated at different moments of their personal life. To give a simplistic example: when war comes, the experience of that event and the impact it has in our lives is not the same depending on whether one is a man of fighting age, a young mother, an infant, or an older person. Thus, we have to consider the nature and synergies of the events that produce changes to the conjunctures, but also how different people are placed differently before them.

This personal positioning with respect to the flow of events in socially scaffolded time is exactly where - or better, when - the concept of generation becomes more relevant for understanding social life. Persons of different ages encounter each conjuncture at different points in their life-course. Continuously flowing historical time and syncopated personal time interact, producing recognisable arrangements with a distinctive generational ambiance. 


\section{Crises, entelechies, generational awareness}

The day-to-day approach to the world of our contemporaries appears commensurable enough. Nevertheless, it is never completely so. The two theorists that we are about to examine were fascinated by this uneven - partially overlapping and partially incommensurable - articulation of understanding of space-time by different generations. José Ortega y Gasset (1883-1955), the Spanish phenomenologist of the 1920s and 1930s, is probably the earlier thinker that fruitfully debated the issue of 'generations' from the perspective of the modern social sciences (see also Marias, 1971; Wohl, 1979). In En torno à Galileo: Esquema de las crisis (1933-4/1982), a set of lectures he delivered whilst in exile in Buenos Aires, he proposes a variant of the Aristotelian idea of 'the three ages of man'. His purpose was to develop a kind of working methodology for the social sciences based on the idea of 'crises of civilisation' (such as the one he was then confronting) and on a phenomenological theory of personhood.

For the purpose of our specific enquiry, Ortega's work is especially useful, as it allows us to link the notions of generation and life-course to a broader view of human history. Since there are many experiences that one only undergoes once in one's life - in Ortega's words, one is never an infant twice - and since those experiences are constitutive of our personhood, each generation is constituted by reference to the conjunctures its members encountered in the different periods of their lives. To the degree that one's existence is structured by particular events, people of different generations differ from each other in understanding their existence in terms of different referents. This personhood-specific view of experience invites us to appreciate why the concept of generations is fundamental for understanding social change and also for understanding personal ontogeny (see Pina-Cabral, 2017).

Furthermore, Ortega's proposal associates the generational effect with power. By correlating the constitution of generations with socio-economic and political change, Ortega moves away from the biologistic emphasis on life-course that was characteristic of authors such as Arnold Van Gennep or Henri-Alexandre Junod at the turn of the twentieth century. He proposes that social life is regularly permeated by moments of rupture in socio-economic and political conditions, which he calls crises. These involve events that cause factors to change in people's lives, giving rise to important transformations. Crises present people with transformative opportunities. As established hegemonies are consequently challenged, forces of opposition emerge upon what Gramsci calls 'the terrain of the conjunctural' (Gramsci, 1973, pp. 178, 210). In this transformational sense, Ortega's use of 'crisis' predates that of Gramsci' and Stuart Hall.

A century later, we are prone to find Ortega's rhythmical view of intergenerational succession perhaps a little too naturalistic. It is based on the premise that people perpetuate social roles through intergenerational succession, e.g. children are supposed to follow their parents' footsteps. The structuralist residue of this idea is visible: individuals slip between generations adopting generational social roles, while the particular society retains its homeostatic consistency. This perspective, which originates in Durkheimian sociology, was put into practice by a mid-twentieth century 'generation' of anthropologists inspired by Parsons. It concerns itself with the sociological parameters of 
inheritance and transmission of property (see, for example, Fortes, 1970). We will return to this shortly.

A contemporary of Ortega, Karl Mannheim (1893-1947), emphatically departed from the cyclical, genealogical conception of generations (see Ryder, 1965). He came to be best known for his writings in the sociology of knowledge. One of his essays - 'The problem of generations' (1952) first published in 1923 - provides us with a robust and explicit analytical discussion of the challenges posed by temporal and age-related social variation. The essay, which only came to general attention in the period after the Second World War, is considered foundational for contemporary sociological treatments of generational differentiation (Bristow, 2016; Edmunds \& Turner, 2005; Pilcher, 1994, 1995). It addresses two problems: (a) how generational awareness is realised (if at all), and (b) how knowledge is transmitted across generations (triggering, in this process, social change).

Like Ortega, Mannheim tackled those problems by grounding the concept of generations not on age-sets or biological cohorts but on the experience of concrete events. He postulated the occurrence of socio-temporal 'generational locations': individuals who share the same circumstances, sensibilities and awareness of change (1923/1952), such as those who came of age during the Napoleonic wars or the First World War. Mannheim's view of the socio-temporal space that he called 'generational location', and the manner in which he anchored generation within it, bears many similarities with our own use of conjuncture. Mannheim did not use Gramsci's or Ortega's work, and he distanced himself from Marx, despite his early association with Georg Lukács (Loader, 1985; Remmling, 1975). In his essay on generations, he drew inspiration from Wilhelm Pinder (1926), an art historian, who used the notion of 'generational entelechy' to refer to generational styles or forms of art. Entelechy, an Aristotelian term, refers to falling within the scope of (or, here, fulfilling) one's purpose. ${ }^{6}$ Mannheim was attracted to Pinder's observation that, due to socio-historical differentiation, not all contemporaries share the same aims or equally represent the spirit of their age; they are, in this socio-cultural sense, non-coevals of their contemporaries.

Mannheim problematised the issue of 'entelechy' sociologically (1923/1952, pp. 283-286, 309-320). He observed that not all generational units realise the potentialities inherent in their generational location. Not all generations share a common awareness and aspirations or achieve generational self-realisation: what Mannheim calls 'generational unity'. Mannheim viewed generational realisation as aspirational - despite its potential to suppress competing or less articulated voices (for example, the peasantry). Falling in with his modernist framework, he perceived various self-aware generational groups as potential agents of 'progress'. They are exemplified by urban youth rebelling against traditionalism and conservatism, mirroring a generational category of which Mannheim felt himself to be a part. ${ }^{7}$ He has been justly criticised for underplaying the importance of class (see Bristow, 2016; Edmunds \& Turner, 2005; Longhurst, 1989) or holding an ambivalent stance to it (Longhurst, 1989, p. 28). Despite that, Mannheim's wider ambition was to refocus his analysis on social consciousness and political awareness, thus evading the class vs generation dilemma (Loader, 1985, p. 84). 


\section{Cycles, strategies and habitus}

In the second half of the 1960s, responding to a historicist critique of Durkheimian structuralism and to the increased individualism that was then dominant in the social sciences, a series of publications appeared that reflected upon generational condition without taking explicit recourse to earlier debates on generation as an analytical category. We have in mind, in particular, Pierre Bourdieu's essays on Béarn (2002, first published in 1962 and 1972) or Jack Goody's work on the developmental cycle of domestic groups (1971). The forerunner of this temporalising rethinking of structuralist assumptions is a 1949 essay by Meyer Fortes (1970). There, he argues in favour of taking into account the implications of life-cycle stages in the study of domestic life among the Ashanti of Ghana. This argument had a profound impact in sociology and anthropology throughout the second part of twentieth century, albeit often unacknowledged. Interestingly, in publications inspired by this view, the concept of generation is omnipresent, but seldom addressed explicitly.

Fortes argued that the cyclical nature of people's increasing authority in the course of their lives means that the development of the primary social units also undergoes structural cycles: households too are dependent on a generational cycle of increasing or declining authority (1970). He revealed the ethnographic source of his inspiration: in Ashanti villages, as male children aged, women's margin for conjugal negotiation increased. Although marriages were initially virilocal, political authority was principally transmitted matrilaterally. So, as their male children grew up and became increasingly involved with their matrilineal relatives, women tended to move to their sons' households, closer to their own brother's residence, where they could achieve a greater level of personal authority. Fortes realised that a synchronic account of how people were distributed between households at any given time would have failed to depict sociologically how households changed their composition in time. It was thus necessary, Fortes argued, to compare the age of the household head (in generational terms) with household composition in order to understand the actual nature of the household as an institution evolving in time. Society, he claimed, was not only structured in space, but also in time.

We limit ourselves here to stressing that Fortes' concern was to explain developmental regularity. This allowed him to identify, on the one hand, a correlation between age and residence and, on the other, between domestic groups and matrilineage. The temporal logic of social organisation that he discovered did not correspond to any explicit norm, or even to any explicit principle of which the Ashanti would be readily aware. Ashanti men and women opted for these modes of action because they seemed more adequate to them for responding to their situational needs. In this way, Fortes hit upon two important notions that were going to have a long future: the notion of the 'developmental cycle of the domestic group' and the notion of 'strategy' as an identifiably recurrent, but not necessarily explicit, process of social response.

In subsequent decades, the notion of strategy was further developed through the works of Pierre Bourdieu, namely through his essays on celibacy in Béarn, the region of France where he was born (2002). Four decades later, he described how he came across the idea: 
One day, while working on a study of male celibacy in Béarn . . . I was chatting with a person who had been one of my most faithful and most intelligent informants - she happened to be my mother. I was not thinking about my study, but I must have been vaguely preoccupied with it, when she said to me in passing, about a family in the village: 'Oh, you know, they've become very kith and kin (très parents) with the So-and-sos [another family in the village] now that there's a polytechnicien in the family.' That remark was the starting-point for the reflection that led me to rethink marriage no longer in terms of the logic of the rule . . . but, against the thenreigning structuralist orthodoxy, as a strategy orientated by specific interests. (2003, pp. 289-290)

Traditionally, landowning parents in Béarn chose a single male heir to their land and sent the other male children to make a living away from home in the towns. This was an age-old practice designed to prevent the household's land from being split between heirs - weakening the household intergenerationally. The paradox that hit Bourdieu so forcefully was that while the heirs to the land were once the most desirable partners, they were now ageing as bachelors. The local women found them less attractive than their landless but urban-savvy brothers and cousins (such as himself, also a polytechnicien). To analyse this generational shift, Bourdieu took recourse to Fortes' method of analysis: he brought systematically together diverse categories of evidence. Triggered by his mother's comment, he concluded that the constraints of matrimonial choices are so complex that they 'exceed the agents' consciousness' (2002, p. 204): various cultural 'principles' come into operation, as people make choices in terms of what they perceive as their interests. The emergence of these 'principles' and the ensuing 'strategies' were then interpreted in the sociocentric fashion that was characteristic of the period. Through Bourdieu's influence and Goody's, this way of thinking about generations spread among anthropologists, social historians and sociologists of the family in the 1980s and 1990s (e.g. Ségalen, 1986).

Retrospectively, we may conclude that the most important aspect of Bourdieu's treatment of generational marriage choices in Béarn is the way in which his notion of strategy leads him to develop his concepts of habitus and of capital (e.g. 2002, p. 249). In Béarn, in the late 1960s, Bourdieu found himself to be a member of a generation divided in its coevalness - in which the heirs to the land, living the traditional life of the countryside, no longer found marriage partners. The scene he describes around the village dance floor, when the pretty girls did not care to dance with the heirs, is a powerful image of the refusal of coevalness. To the contrary, those such as him, the family's least favoured children, whose parents had sent them away from home, turned out ironically to constitute the generational sector that assumed hegemony. The generational habitus of Bourdieu's own post-war generation was divided between two forms of life and, therefore, there arose two distinct generational sub-conditions - they were contemporaries, but not coevals.

Through this example, Bourdieu captures brilliantly the way in which taste reflects power. But he appears to have struggled with the plural and multilevelled articulation of power: that is, hegemonies function within hegemonies in processes of embracement and encompassment that are constantly being recreated; a point that Raymond Williams and Stuart Hall have accentuated, following Gramsci. Bourdieu, although successful in 
identifying the nature of the conjunctural choices, remained uncomfortable about the exact location of his own generational conjuncture. ${ }^{8}$ This is why, as we read Bourdieu's essays on celibacy in Béarn, we are struck by how he sees himself as an 'agent', but we also note how his account is part of the imposition of the new habitus that is pushing those previously favoured community leaders to the periphery. It is at this point that we choose to see Bourdieu himself not simply as an 'agent/actor', but rather as an emergent entity in generational terms. He is emerging intergenerationally as he is writing his texts, along with his siblings, the girls that prefer to dance with him rather than the heirs to the land, and all other persons in Béarn, who are all equally involved in that generational conjuncture.

\section{Raymond Williams and structures of feeling}

What Bourdieu left unresolved - his ambivalence towards participation and affective attunement in the work of hegemonies that replace each other - leads us to seek answers in the views of Raymond Williams (1921-1988), another member of the generation that came of age during the Second World War. As an academic, novelist, literary critic, activist and undogmatic Marxist, Williams can be described - in Gramscian terms - as a true organic intellectual. His concern with generational social change (more specifically, generation-specific dramatic conventions) led to a valuable analytic intervention in thinking about generations. We will focus here on a particular analytic notion he introduced, which has a distinctive generational flavour: structure of feeling. The concept first appears in A Preface to Film (Williams \& Orrom, 1954) ${ }^{9}$ and then reappears consistently in later work (Williams, 1977, 1979). It refers to a feeling of a generational style or language of artistic expression that is about to emerge (or is emerging) at a particular period. A structure of feeling is not explicitly (or narrowly) definable, imprisoned in singular institutions or beliefs - it is generational to the extent that it marks a group of people whose interventions in the world are proximate. The value of the concept for Williams lies precisely in its ability to embrace the subtle differentiations and overlaps that mark generational understandings of convention - common evaluations and recognitions, but also entanglements with class and power - that make sense to people who have experienced a distinct period. It is this sense-making quality that makes the concept useful and applicable beyond the analysis of artistic production for it suggests sympathy both in modes of rationality and in affective attunement. ${ }^{10}$

The elusiveness of 'structure of feeling' as an analytical concept is rooted in the fluid interrelationship between different generational experiences. As with Ortega and Mannheim, Williams is aware of the simultaneous coevalness and lack of coevalness that separates and unites overlapping generations (or parts of the same generation that occupy different positions in the constellation of power). This is why Williams refuses to narrowly pinpoint his use of structures of feeling in a closed definition; by the time a structure of feeling becomes clearly articulated, he explains, it may be already about to be replaced by another (1977, pp. 128-133). Williams avoids committing himself to a total definition (see Williams, 1979), advising instead that it is preferable to evade static and singular conceptualisations of culture and society (Williams, 1977). His use of the term 'feeling' bears some similarity to the term 'experience', although the latter, he clarifies, 
is often grounded in the past, and in this respect it is conceived in more static terms. This pastness of 'experience' does not exactly fit the open sense of meaningfulness that Williams is trying to convey with 'structure of feeling' (1977, pp. 128, 132; Higgins, 1999). Instead, he chooses the term 'feeling' to convey this imprecise, not always fully or clearly articulated understanding that emerges in particular periods in response to shared challenges - one that conjoins reason and affect. ${ }^{11}$

We can easily outline several advantages for using 'structures of feeling' in generational analysis. For example, might it not be arguable that the heightened awareness to climate emergency - or even, the urgency to decolonise academic thinking - that we are presently witnessing is a generational structure of feeling? As an intermediate category in the making, a structure of feeling can provide scope to navigate between other wellformed concepts - for example, ideology or worldview - before these are formalised. This open-ended analytical perspective has an additional benefit: it can draw attention to the relational dimension of generational comparisons and their articulation with power. As Williams himself underlined, a structure of feeling depends upon the previous conventions it attempts to replace (Williams \& Orrom, 1954). This observation allows us to contemplate - with Gramsci in mind - two important possibilities. The structure of feeling of any particular generation is (1) undoubtedly entangled with previous and current hegemonic conventions, and (2) may potentially engender a conjunctural moment of nonconformity - which may inspire some transformation - even whilst it might eventually be co-opted or conventionalised. This opportunity is sometimes taken, and just as often lost, but it becomes more readily available in times of crises, as the work of Stuart Hall can help us appreciate.

\section{Stuart Hall and conjunctural articulation}

It is a matter of logical progression for us to move from Raymond Williams to Stuart Hall (1932-2014), another scholar inspired by Gramsci. Hall took from Gramsci the notion of conjuncture and developed it as a versatile analytical tool that can provide a non-reductive, historically informed and contextual view of crisis and social transformation. His use of conjuncture is premised on a decision taken by the analyst to focus on a particular assemblage of circumstances that provide, in their articulation, plural explanatory threads - e.g. historical, cultural, or economic. These can elucidate the workings of social life as a field of power. His classic analyses of the conditions that gestated the emergence of Thatcherism in the 1970s (see Hall, 1990, 2017a; Hall et al., 1978) serve as leading examples of this approach, which has since been applied by sociologists and geographers to reflect upon contemporary crises (Grayson \& Little, 2017), including Brexit, in the UK case (Clarke, 2019; Virdee \& McGeever, 2018).

We can trace Hall's early interest in the problems structured by the concept of generation in a collaborative volume, Resistance Through Ritual (see Clarke et al., 1976). Unhappy with common-sense conceptualisations of Youth Culture in the media, the authors argued that the narrow association of a generation with particular sets of subcultural preferences or social concerns can hide from our view the articulation of multiple social forces and relationships, leading to a class-less representation of generational phenomena. The approach taken was ahead of its time, not only in denaturalising, but 
also in re-temporalising generation intersectionally within conjunctural configurations of power: a generation - as indicative of an age-set - should not be conceived in isolation from race or class or what comes from before (or is likely to follow), such as, for example, the discrimination of black urban youth (Hall et al., 1978, pp. 339-340).

Towards the end of his life Hall referred to generation as a concept indicative of something more than mere chronology: 'it is symbolic rather than linear,' he said, 'relating as much to a shared experience, a common vision, or thinking within the same "problem space" as it does to a mere date of birth' (Hall, 2017b, p. 44). This is an experience-rich view of generation that focuses on coevalness, explicitly departing from what has been called generationalism, with its focus on contemporaneity. As we mention above, the vehicle that led Hall to this plastic view of generation - thus unburdening Bourdieu's agony about the interface of structure and agency - is his conjunctural perspective, which brought him face to face with concrete examples and unmediated processes. Each conjuncture comes with analytical scope to pull different interpretive threads - the broader, plural, non-prescriptive determinants that elucidate the predicaments of specific groups. We would like to add that the conjuncture, seen as a 'problem space', provides scope for the analysts to reveal their identity within the analysis itself. Hall is a social actor - in Bourdieu's terms - participating in, but without hiding himself from, the politics of representation. He is aware of his generational location - a last colonial generation, just before the postcolonials - as he admits with disarming autobiographical reflexivity (Hall, 2017b, pp. 45-46).

Seen in such flexible terms, Hall's conjunctures operate as anchors that locate analyses in relational processes. To identify a conjuncture amounts to proposing a reflexive space-time to think about social conditions. This is a mode that is more specific than the longue durée and more expansive than the event (Braudel, 1980; Sahlins, 1985), or in between the specificity of the moment and the long-term scope of the epoch (Grossberg, 2019, p. 42). Hall does not specify the length of a conjuncture (Clarke, 2014, p. 115; 2017, p. 83; Gilbert, 2019, pp. 8-9; Hall, 1990, p. 130; Hall \& Massey, 2010, p. 57) - it can be shorter or longer, but usually it is conceived as a dynamic transformative period. What is important for Hall in the idea of a conjuncture is the possibility of framing and elucidating the intersection of other analytic categories, for example, class, race and ethnicity (2017c). In this manner, conjunctural analysis takes as accepted that, beyond explicit conscious intention, relations are framed in such ways that subjects are differently placed within the social terrain. In this respect, the concept of conjuncture temporalises structural inequality (e.g. Grodsky \& Pager, 2001; Sørensen, 1996), for it reveals how this exists in relation to moments of relative structural stability.

Indeed, as Sahlins famously argued, conjunctures have structure, which is 'the practical realization of the cultural categories in a specific historical context, as expressed in the interested action of the historic agents, including the microsociology of their interaction' (1985, p. xiv). In light of that, the category of generation can provide historic depth to conjunctural analysis, countering the possibility of the analytical loss of persons (and their affectively infused intentions) in the interpretative synthesis of the wider determinations. Adding a generational angle to conjunctural analysis, we suggest, may help alleviate the conjunctural abstraction, redirecting attention to how circumstances condensed with meaning are 'felt and lived' (Williams, 1977); for example, by persons whose 
ontogeny relates creatively (spatially and temporally) with others. A 'comparative' conjunctural approach that interweaves local perspectives with those of the analyst can make visible how one generational conjuncture depends upon the articulation of previous and successive conjunctures - and, thus, the interplay of partially overlapping, and temporally syncopated structures of feeling.

\section{Conclusion}

Twentieth century social theory provided us with a significant set of lessons concerning generations that allow us to free ourselves from the concept's original naturalising implications: we have in mind Gramsci's and Ortega's interest in crises as transformative moments, Mannheim's fascination with generational awareness, Bourdieu's attention to strategic agency, Williams' notion of structures of feelings, and Hall's intersectional treatment of conjunctures. These thinkers encouraged us to adopt interpretative strategies that bring to the forefront the relationship of generational experiences with historicity and power. Undoubtedly, their thinking is underpinned by different priorities - e.g. Gramsci's inspiration is primarily political, while Bourdieu is led by sociological observations; Hall and Williams tread productively between political engagement and academia. Yet, a common thread in their thinking was the contradictions that emerge from the awareness of contemporaneity and generational overlap. The latter was also a uniting theme in our analysis, which employed the notion of coevalness to add analytical clarity to the intersecting nuances of contemporaneity.

Coevalness, as introduced by Fabian's ethical-cum-political stance (1983), allowed us to expand beyond a sociocentric, chronological understanding of social coexistence. The notion encourages social analysts to address the complexity of temporal coexistence: the contemporaneity of experiences of community, but also the awareness of living together (or not) in the same ethical time. We can clearly see these productive contradictions in Bourdieu's 'revelatory incident' (Fernandez, 1986) in his mother's kitchen. At that moment, he realised that the domestic habitus within which he had been raised was being eroded - not merely by economic and political structures, but also by a structure of affects, values and tastes; observations that inspired his later work. Bourdieu was contemporary with the heirs of the past in Béarn, yet not their coeval. Contrastingly, the two authors of this article, despite having been born in different countries and decades, have been in company during (at least) three marked crises: they shared the same structure of feeling (the same vigencia, in Ortega's words) about austerity (in their countries of origin), about Brexit, and about the pandemic. Yet, this did not reduce that which differentiates them.

It seems important, therefore, to approach generational participation in fluid, processual and conjunctural terms. Reified, generalised generations - Generation X, Y, or Z, such as represented by the generationalist arguments so common in the media - can only hide from view the nuanced complexity of sociation (see Bristow, 2020; Hazlett, 1998; Purhonen, 2016; White, 2013), including the subtle hierarchies structured by class and other intersectional features. This is why we argue that a naturalised understanding of generation is reductive. It denies coevalness and padlocks social agents into rigid divisions - something Williams abhorred. By thinking about generations conjuncturally, we 
can escape univocal, closed interpretations of social life, but also manage to trace the subtle process within which each reigning hegemony corresponds to constantly evolving structures of feeling - that is, the permanent articulation between previously commensurable meaning and the newly shared perspectives that are constantly replacing it. Stuart Hall's conjunctural perspective provides guidance and inspiration in this respect.

Our argument in this article is that we can turn into an analytical advantage the very limitations of the concept of generation - its semantic imprecision, the potential overlap of different intersectional or ideological features (Edmunds \& Turner, 2002; Williams, $1976 / 1983$ ), or the way it integrates frames of classification with affective responses. The underdetermination of generation is a function of the complex interaction between coevalness and contemporaneity in everyday social life. Rather than being an insurmountable problem, the complexity allowed by the underdetermination of generations opens analytical space for intersectional referents of personal experience (inter alia, gender, class, race/ethnicity), without closing them within singular, overdetermined explanatory frameworks. As emergent entities within social life, generations invite critical attention to the inexhaustible, layered nature of sociation out of which emerge constellations of meaning and power. Such a view can facilitate a decolonising perspective that uncovers modernist naturalisations, in line with a critique of hierarchical views of intergenerational succession as indicative of 'progress' or 'development' (where the latter are defined according to 'Western' technological or liberal-economic referents).

For this reason, we feel that the concept of generation deserves a place in our analytical vocabulary - not merely as a descriptive qualification, but as a dynamic, sense-making tool for analysis - as an intermediate category. So long as we remain within an epistemological disposition that separates models from experiences, signifiers from signified, and words from deeds, we will be incapable of grasping the way in which 'structures of feeling', strategic agencies, generational conjunctures simultaneously 'are' real, but also 'are' conceived. Thus, to use Edwin Ardener's terms (1989/2007, p. 87), 'generations' are not merely an analytic construct; they are also a 'mode of registration': they shape our definition of 'events' and play a part in our strategic positioning by relation to the conjunctures we encounter.

In moments of crisis and protracted austerity - such as those that have marked the past decade in Europe - the matter of generation and of generational attunement becomes unavoidable. Those who came of age in Europe during the most recent austerity crisis also found themselves in the midst of a pandemically produced recession, and a political crisis of the democratic institutions that will deeply affect their future lives as citizens (see Pina-Cabral, 2018). The conjoined effects of these crises will leave an indelible mark on more than one generation. Yet they will do so differently and differentially, inviting varying opportunities for transformation and consequent strife (Clarke, 2014; Grayson \& Little, 2017; Hall \& Massey, 2010).

Not every contemporary generation will respond similarly. To the contrary, relative coevalness means that generational differentiation is permanently on the go: generational styles and concerns 'fade, disappear or are so widely diffused that they lose their distinctiveness' (Clarke et al., 1976, p. 14). Differently placed contemporaries address similar challenges in different modes. Present-day generational grievances, expressed in the form of 'intergenerational discounting' through social media (Elliott, 2021), will merge into 
other concerns as issues mutate in the media. They will, however, affect the lives of those who experience it and those who are subject to it, giving rise to structures of feeling that, in turn, will move people's awareness of who is 'like them' and who is not. The degree to which the current crises will promote a commensurability between emerging and overlapping structures of feeling remains to be seen. But we can say with some certainty - returning to our opening quote from the Guardian - that all generations, not merely current ones, will eventually be 'lost'. They will be replaced, gradually, by new ones, born out of moments of encounters of coevalness, within a process in which one hegemony succeeds another (as hegemonies confront the hegemonies that emerge within and beyond them). Social scientists - as well as politically engaged and informed citizens - cannot control this process, but we can work together to understand its nuanced complexity, refining our conceptual tools and thus sharpening our ethical engagements.

\section{Funding}

The research on which this work was based was supported by UK's Economic and Social Research Council (ESRC, research grant ES/L005883/1). Dimitrios Theodossopoulos has a secondary affiliation with the Smithsonian Tropical Research Institute, Panama, while João Pina-Cabral is also Emeritus Professor at the University of Kent.

\section{Notes}

1. In this regard, we are mindful that the notion of 'lost generation' may be potentially problematic - in that it could 'serve to uphold a rhetoric of inevitability' (Nilsen \& Brennan, 2014).

2. The bibliography is vast but, for cohorts, see Ryder (1965), and for an inspirational study of life-course, see Elder (1999).

3. See Hall (2017a, 2017c), Hall \& Massey (2010), Clarke (2014, 2017), Grossberg (2017, 2019) and Gilbert (2019).

4. Gramsci's notion that 'individuals' perceive their lives by relation to different times, thus being characterised by 'temporal plurality', is a valuable contribution (see Filipini, 2017, p. 109).

5. Although written in the late 1930s, Gramsci's Prison Notebooks where only published in the 1950s in Italian and their principal impact in the social sciences dates to the first English translations in the late 1950s and 1973 (1992, I, p. xiii).

6. Entelechy from Greek (entelékheia): en- (within), telos (end, destiny), ekhein (to have, be in a state of).

7. A member of a Jewish, urban middle class in continental Europe that grew to become a liberal, avant-garde urban intelligentsia in the 1920s (see also Loader, 1985; Remmling, 1975).

8. As Purhonen (2016) observed, Bourdieu's theoretical contribution to the discussion about generations is less formative if we narrowly focus on those parts of his work that directly refer to the term - and more influential if we approach his work more inclusively.

9. See 'Film and the dramatic traditions' in Preface to Film (1954).

10. Williams did not produce an explicit theory on generations, but he dedicated an entry to the concept in his revised edition of Keywords (1983), where he encourages his readership to conceive the term in a fluid manner and beyond its biological referents.

11. At this point, it is worthwhile noting that Ortega's concept of vigencias (roughly translatable as 'things that are valid'), as used for example by Lisón-Tolosana in studying different gendered approaches to personal value (1966/1988, p. 337), is interestingly close to the main drive of Williams' notion of 'structures of feeling'. 


\section{References}

Ardener, E. (2007). The voice of prophecy and other essays. Berghahn.

Barad, K. (2007). Meeting the universe halfway. Duke University Press.

Bourdieu, P. (1988). Homo academicus. Polity Press.

Bourdieu, P. (2002). Le bal des célibataires: crise de la société paysanne en Béarn [The bachelors' ball: the crisis of peasant society in Béarn]. Seuil.

Bourdieu, P. (2003). Participant objectivation. Journal of the Royal Anthropological Institute (N.S.), 9, 281-294

Braudel, F. (1980). On history. University of Chicago Press.

Bristow, J. (2016). The sociology of generations: New directions and challenges. Palgrave.

Bristow, J. (2020). Post-Brexit boomer blaming: The contradictions of generational grievance. The Sociological Review, 69(4), 759-774.

Burnett, J. (2016). Generations: The time machine in theory and practice. Routledge.

Clarke, J. (2014). Conjunctures, crises, and cultures. Focaal, 70, 113-122.

Clarke, J. (2017). Doing the dirty work: The challenges of conjunctural analysis. In J. Henriques \& D. Morley, with V. Goblot (Eds.), Stuart Hall: Conversations, projects and legacies (pp. 79-84). Goldsmiths Press.

Clarke, J. (2019). A sense of loss? Unsettled attachments in the current conjuncture. New Formations, 96-97, 132-146.

Clarke, J., Hall, S., Jefferson, T., \& Roberts, B. (1976). Subcultures, cultures and class: A theoretical overview. In S. Hall \& T. Jefferson (Eds.), Resistance through rituals: Youth subcultures in post-war Britain (pp. 9-74). Huchinson \& Co.

Edmunds, J., \& Turner, B. (2002). Introduction: Generational consciousness, narrative, and politics. In J. Edmunds \& B. Turner (Eds.), Generational consciousness, narrative, and politics (pp. 1-12). Rowman \& Littlefield.

Edmunds, J., \& Turner, B. (2005). Global generations: Social change in the twentieth century. British Journal of Sociology, 56(4), 559-577.

Elder Jr., G. H. (1999). Children of the Great Depression: Social change and life experience. Westview.

Ellen, R. (2012). Nuaulu religious practices. Brill.

Elliott, R. (2021). The 'Boomer remover': Intergenerational discounting, the coronavirus, and climate change. The Sociological Review. Advance online publication. https://doi. org/10.1177/00380261211049023

Fabian, J. (1983). Time and the other. Columbia University Press.

Fernandez, J. (1986). Persuasions and performances: The play of tropes in culture. Indiana University Press.

Filipini, M. (2017). Using Gramsci: A new approach. Pluto Press.

Fortes, M. (1970). Time and social structure and other essays. Athlone.

Gilbert, J. (2019). This conjuncture: For Stuart Hall. New Formations, 96-97, 5-37.

Goody, J. (Ed.). (1971). Developmental cycle in domestic groups. Cambridge University Press.

Gramsci, A. (1973). Selections from the prison notebooks (Ed. and Trans. Q. Hoare \& G. N. Smith). International Publishers.

Gramsci, A. (1992). Prison notebooks (3 vols, Ed. J. Buttigieg \& A. Callari). Columbia University Press.

Grayson, D., \& Little, B. (2017). Conjunctural analysis and the crisis of ideas. Soundings, 65, $59-75$.

Grodsky, E., \& Pager, D. (2001). The structure of disadvantage: Individual and occupational determinants of the black white wage gap. American Sociological Review, 66(4), 542-567. 
Grossberg, L. (2017). Wrestling with angels of cultural studies. In J. Henriques \& D. Morley, with V. Goblot (Eds.), Stuart Hall: Conversations, projects and legacies (pp. 105-116). Goldsmiths Press.

Grossberg, L. (2019). Cultural Studies in search of a method, or looking for conjunctural analysis. New Formations, 96-97, 38-68.

Hall, S. (1990). The hard road to renewal: Thacherism and the crisis of the left. Verso.

Hall, S. (2017a). The fateful triangle: Race, ethnicity, nation. Harvard University Press.

Hall S. (with B. Schwarz). (2017b). Familiar stranger. Allen Lane.

Hall, S. (2017c). Selected political writings. Lawrence \& Wishart.

Hall, S., Critcher, C., Jefferson, T., Clarke, J., \& Roberts, B. (1978). Policing the crisis. Macmillan.

Hall, S., \& Massey, D. (2010). Interpreting the crisis. Soundings, 44, 57-71.

Hazlett, J. D. (1998). My generation: Collective autobiography and identity politics. University of Wisconsin Press.

Higgins, J. (1999). Raymond Williams. Routledge.

Hirsch, E., \& Stewart, C. (2005). Introduction: Ethnographies of historicity. History and Anthropology, 16(3), 261-274.

Kertzer, D. I. (1983). Generation as a sociological problem. Annual Review of Sociology, 9, 125149.

Lamb, S. (2015). Generation in anthropology. In J. Wright (Ed.), International encyclopedia of the social and behavioral sciences (pp. 853-856). Elsevier.

Lisón-Tolosana, C. (1988). Belmonte de los Caballeros: Anthropology and history in an Aragonese community. Princeton University Press (Original work published 1966).

Loader, C. (1985). The intellectual development of Karl Mannheim: Culture, politics and planning. Cambridge University Press.

Longhurst, B. (1989). Karl Mannheim and the contemporary sociology of knowledge. Macmillan.

Mannheim, K. (1952). The problem of generations. In P. Keckskemeti (Ed.), Essays on the sociology of knowledge (pp. 276-320). Routledge (Original work published 1923).

Marias, J. (1971). Generations: A historical method. University of Alabama Press.

Mintz, S. (1996). Enduring substances, trying theories: The Caribbean region as Oikoumene. Journal of the Royal Anthropological Institute N.S., 2, 289-293.

Needham, R. (1974). Age, category, and descent. In Remarks and inventions: Skeptical essays about kinship (pp. 71-107). Tavistock.

Nilsen, A., \& Brennan, J. (2014). An intergenerational approach to transitions to adulthood: The importance of history and biography. Sociological Research Online, 19(2), 9.

Ortega y Gasset, J. (1982). En torno a Galileo (Esquema de las Crisis) [About Galieo (Outline of a crisis)]. Alianza Editorial (Original work published 1933-1934).

Palmié, S., \& Stewart, C. (2016). Introduction: For an anthropology of history. HAU: Journal of Ethnographic Theory, 6(1), 207-236.

Pilcher, J. (1994). Mannheim's sociology of generations: An undervalued legacy. The British Journal of Sociology, 45(3), 481-495.

Pilcher, J. (1995). Age and generation in modern Britain. Oxford University Press.

Pina-Cabral, J. (2014). Lusotopy as ecumene. In T. H. Eriksen, C. Garton \& S. Randeria (Eds.), Anthropology now and next: Essays in honor of Ulf Hannerz (pp. 241-263). Berghahn Books.

Pina-Cabral, J. (2017). World: An anthropological examination. HAU Books.

Pina-Cabral, J. (2018). Familial persons in dark times. Social Anthropology, 26(3), 376-390.

Pina-Cabral, J., \& Bowman, G. (Eds.). (2020). After society: Anthropological trajectories out of Oxford. Berghahn.

Pina-Cabral, J., \& Lima, A. P. (2000). Elites: Choice, leadership and succession. Berg. 
Pinder, W. (1926). Kunstgeschichte nach Generationen [Art history by generations]. Eduard Pfeiffer.

Purhonen, S. (2016). Generations on paper: Bourdieu and the critique of 'generationalism'. Social Science Information, 55(1), 94-114.

Remmling, G. W. (1975). The sociology of Karl Mannheim. Routledge.

Riehl, J. P. (2010). Mirror-image asymmetry: An introduction to the origin and consequences of chirality. Wiley.

Ryder, N. B. (1965). The cohort as a concept in the study of social change. American Sociological Review, 30(6), 843-861.

Sahlins, M. (1985). Islands of history. University of Chicago Press.

Ségalen, M. (1986). Historical anthropology of the family. Cambridge University Press.

Sørensen, A. B. (1996). The structural bases of social inequality. American Journal of Sociology, 101(5), 1333-1365.

Stewart, C. (2016). Historicity and anthropology. Annual Review of Anthropology, 45, 79-94.

Theodossopoulos, D. (2020). Iphigenia's sacrifice: Generational historicity as a structure of feeling in times of austerity. The Journal of Royal Anthropological Institute, 26(4), 842-863.

Turner, B. (2002). Strategic generations: Historical change, literary expression, and generational politics. In J. Edmunds \& B. Turner (Eds.), Generational consciousness, narrative, and politics (pp. 13-30). Rowman \& Littlefield.

Van Gennep, A. (1909). Les rites de passage. Émile Nourry.

Virdee, S., \& McGeever, B. (2018). Racism, crisis, Brexit. Ethnic and Racial Studies, 41(10), $1802-1819$.

White, J. (2013). Thinking generations. British Journal of Sociology, 64(2), 216-247.

White, J. (2017). Climate change and the generational timescape. The Sociological Review, 65(4), $763-778$

Williams, R. (1977). Marxism and literature. Oxford University Press.

Williams, R. (1979). Politics and letters. Verso.

Williams, R. (1983). Keywords. Oxford University Press (Original work published 1976).

Williams, R., \& Orrom, M. (1954). A preface to film. Film Drama Limited.

Wohl, R. (1979). The generation of 1914. Harvard University Press. 